\title{
Gastrointestinal hemorrhage caused by the direct invasion of a hepatocellular carcinoma successfully treated with polyglycolic acid sheet shielding
}

A 76-year-old man with a history of alcoholic liver cirrhosis presented with a 4-day history of melena. He had been diagnosed 30 months previously with hepatocellular carcinoma (HCC), but chose to not receive further evaluation or treatment. Laboratory findings revealed severe anemia (hemoglobin $4.9 \mathrm{~g} / \mathrm{dL}$ ) and liver dysfunction. A computed tomography (CT) scan demonstrated an enlarged HCC mass (10-cm diameter) located in the left lobe of the liver, compressing the stomach ( $\mathbf{F i g} \mathbf{1}$ ). Esophagogastroduodenoscopy (EGD) detected a submucosal tumor with central ulceration in the lesser curvature of the stomach ( $\triangleright$ Fig. 2).

The patient was diagnosed with upper gastrointestinal (Gl) hemorrhage caused by direct HCC invasion and angioembolization was performed to promote hemostasis. However, a follow-up CT scan revealed that the perigastric portion of the HCC remained viable and the possibility of recurrent bleeding remained a concern. In response, a polyglycolic acid (PGA) sheet (Neoveil; Gunze Co., Kyoto, Japan) and fibrin glue were endoscopically applied to the ulcerous lesion ( $\vee$ Video 1), implementing a method used in previous studies [1,2]. An EGD

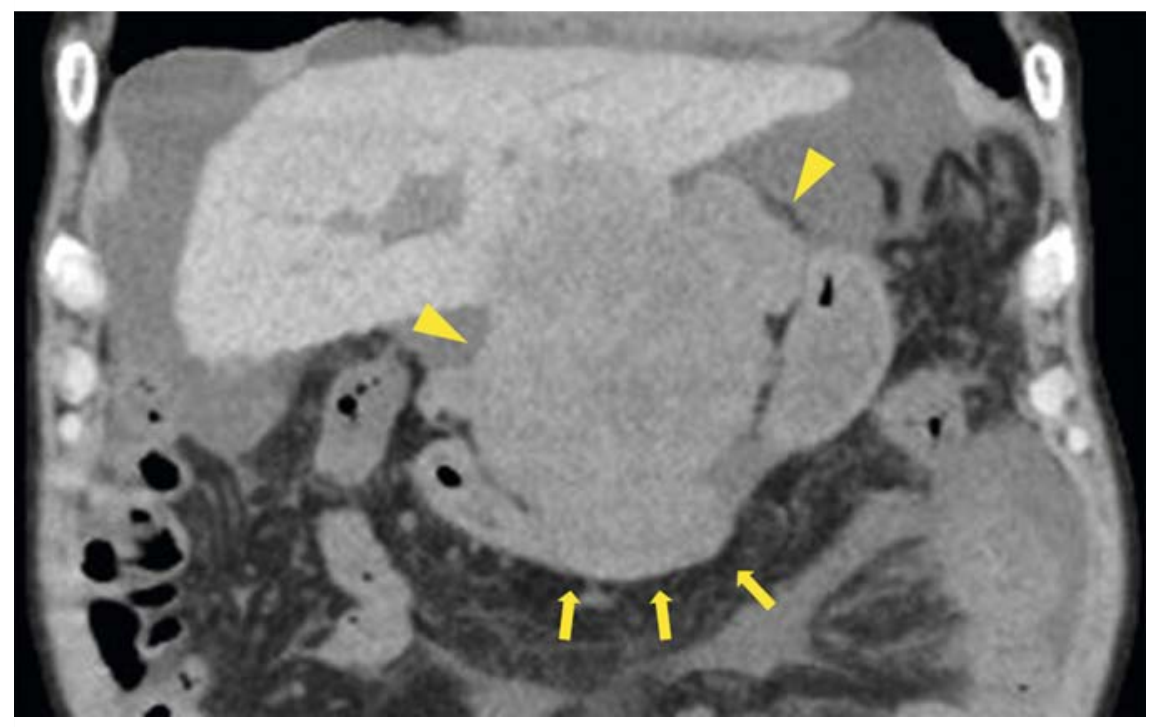

- Fig. 1 Computed tomography scan of the abdomen showing a markedly enlarged hepatocellular carcinoma in the left lobe (arrowhead), approximately $10 \mathrm{~cm}$ in diameter, which was compressing the stomach (arrows).

2 days after the procedure showed that the PGA sheet remained intact.

The patient opted to be discharged and received palliative medical care at home. He had no subsequent recurrence of melena prior to his death from hepatic failure 14 days after the procedure.
$\mathrm{HCC}$ with direct invasion into the stomach is very rare and the prognosis is ominous owing to poor hepatic reserve and continuous bleeding from the lesion [3]. Moreover, a nonsurgical treatment, such as angioembolization, does not always achieve complete hemostasis [4]. Application of PGA sheets has been used to prevent per-
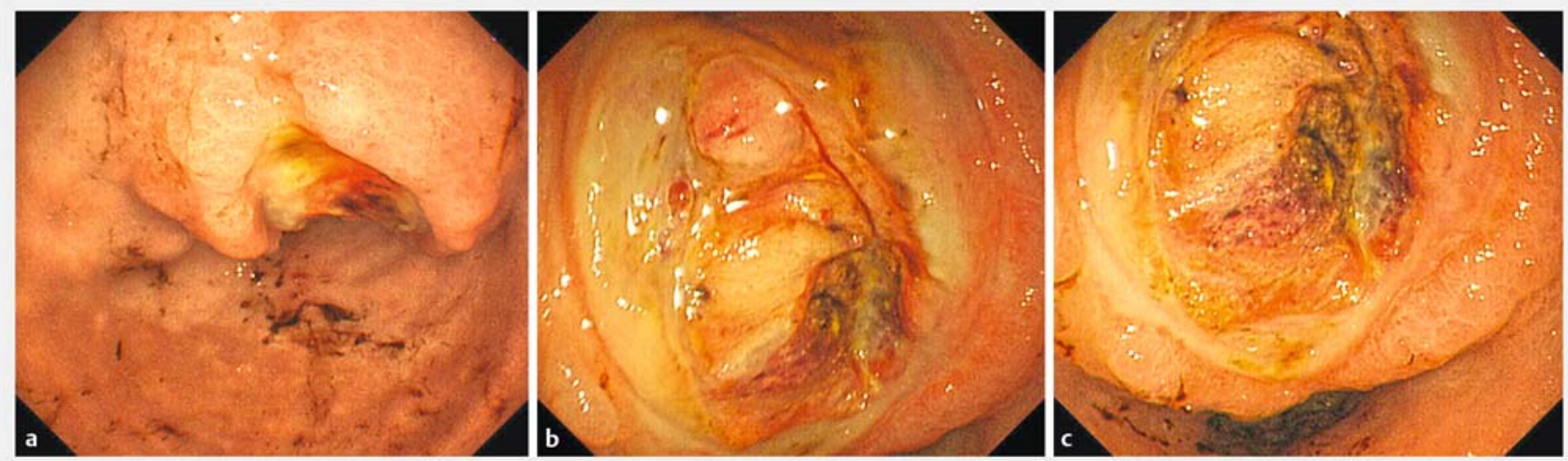

- Fig. 2 Endoscopic views showing: a a submucosal tumor with central ulceration in the lesser curvature of the stomach; b, $\mathbf{c}$ infiltrating irregular reddish-white tumor with partial necrosis, showing intermittent blood oozing. 


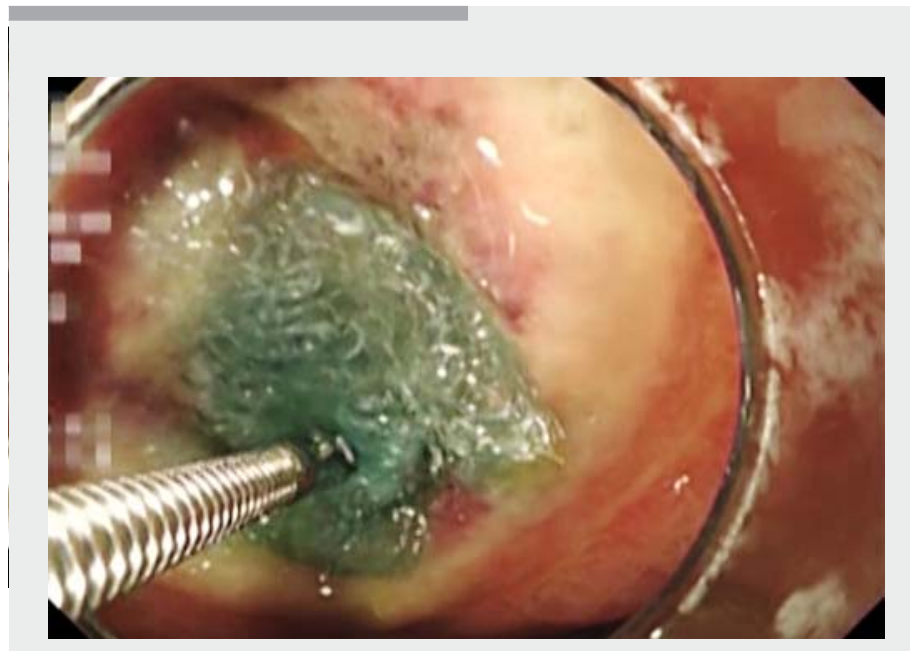

Video 1 Endoscopic shielding of a hemorrhagic gastric ulcer due to invasive hepatocellular carcinoma using polyglycolic acid (PGA) sheet and fibrin glue.

foration, stricture, or bleeding after endoscopic submucosal dissection (ESD) $[1,2]$ and has effectively repaired GI fistulas and perforated post-ESD ulcers [5]. Therefore, the endoscopic application of PGA shielding for patients with HCC and direct GI invasion may be considered as the conservative treatment of choice.

Endoscopy_UCTN_Code_TTT_1AO_2AD

\section{Competing interests}

None

The authors

Tomohiko Mannami1,2, Nobukiyo Fujiwara', Genyo Ikeda', Takahito Mishima', Taiga Kuroi $^{1}$, Takayuki Muraoka ${ }^{3}$, Yasuyuki Ohtawa ${ }^{3}$

1 Department of Internal Medicine, Chugoku Central Hospital, Fukuyama, Japan

2 Department of Gastroenterology, National Hospital Organization Okayama Medical Center, Okayama, Japan

3 Department of Surgery, Chugoku Central Hospital, Fukuyama, Japan

\section{Corresponding author}

\section{Tomohiko Mannami, MD, PhD}

Department of Gastroenterology, National Hospital Organization Okayama Medical Center, 1711-1 Tamasu, Kita-ku, Okayama 701-1192, Japan

Fax: +81-86-2949255

tmannami-gi@umin.ac.jp

\section{References}

[1] Takimoto K, Toyonaga T, Matsuyama K. Endoscopic tissue shielding to prevent delayed perforation associated with endoscopic submucosal dissection for duodenal neoplasms. Endoscopy 2012; 44: E414 - E415

[2] Ono S, Tsuji $Y$, Fujishiro $M$ et al. An effective technique for delivery of polyglycolic acid sheet after endoscopic submucosal dissection of the esophagus: the clip and pull method. Endoscopy 2014; 46: E44-E45

[3] Chen LT, Chen CY, Jan CM et al. Gastrointestinal tract involvement in hepatocellular carcinoma: clinical, radiological and endoscopic studies. Endoscopy 1990; 22: 118 123
[4] Fujii K, Nagino M, Kamiya J et al. Complete resection of hepatocellular carcinoma with direct invasion to the stomach remnant. J Hepatobiliary Pancreat Surg 2004; 11: 441 444

[5] Ono H, Takizawa K, Kakushima $\mathrm{N}$ et al. Application of polyglycolic acid sheets for delayed perforation after endoscopic submucosal dissection of early gastric cancer. Endoscopy 2015; 47: E18 - E19

\section{Bibliography}

DOI https://doi.org/10.1055/a-0747-5467

Published online: 23.11.2018

Endoscopy 2019; 51: E20-E21

(c) Georg Thieme Verlag KG

Stuttgart · New York

ISSN 0013-726X

\section{ENDOSCOPY E-VIDEOS \\ https://eref.thieme.de/e-videos}

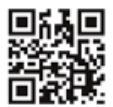

Endoscopy E-Videos is a free access online section, reporting on interesting cases and new techniques in gastroenterological endoscopy. All papers include a high quality video and all contributions are freely accessible online.

This section has its own submission website at https://mc.manuscriptcentral.com/e-videos 